\title{
Siderophore-Producing Bacteria from a Sand Dune Ecosystem and the Effect of Sodium Benzoate on Siderophore Production by a Potential Isolate
}

\author{
Teja Gaonkar, Pramoda Kumar Nayak, Sandeep Garg, and Saroj Bhosle \\ Department of Microbiology, Goa University, Taleigao Plateau, Goa 403 206, India \\ Correspondence should be addressed to Saroj Bhosle, sarojbhosle@yahoo.co.in
}

Received 28 October 2011; Accepted 12 December 2011

Academic Editor: Bernard Paul

Copyright () 2012 Teja Gaonkar et al. This is an open access article distributed under the Creative Commons Attribution License, which permits unrestricted use, distribution, and reproduction in any medium, provided the original work is properly cited.

\begin{abstract}
Bioremediation in natural ecosystems is dependent upon the availability of micronutrients and cofactors, of which iron is one of the essential elements. Under aerobic and alkaline conditions, iron oxidizes to $\mathrm{Fe}^{+3}$ creating iron deficiency. To acquire this essential growth-limiting nutrient, bacteria produce low-molecular-weight, high-affinity iron chelators termed siderophores. In this study, siderophore-producing bacteria from rhizosphere and nonrhizosphere areas of coastal sand dunes were isolated using a culturedependent approach and were assigned to 8 different genera with the predominance of Bacillus sp. Studies on the ability of these isolates to grow on sodium benzoate revealed that a pigmented bacterial culture TMR2.13 identified as Pseudomonas aeruginosa showed growth on mineral salts medium (MSM) with $2 \%$ of sodium benzoate and produced a yellowish fluorescent siderophore identified as pyoverdine. This was inhibited above $54 \mu \mathrm{M}$ of added iron in MSM with glucose without affecting growth, while, in presence of sodium benzoate, siderophore was produced even up to the presence of $108 \mu \mathrm{M}$ of added iron. Increase in the requirement of iron for metabolism of aromatic compounds in ecosystems where the nutrient deficiencies occur naturally would be one of the regulating factors for the bioremediation process.
\end{abstract}

\section{Introduction}

Sand dune ecosystems are described as mounds of sand with vegetation, found along the coastal areas [1]. Dunes are characterized by low nutrients, drought, high salinity, and sand erosion. Plants growing in sand dune habitat help in stabilization of the same, and are controlled by the interaction between, biotic and physicochemical components of sand matrix [2]. Low iron content is a peculiar feature of rhizosphere of such plants. Iron-limiting conditions influence the efficiency of microbial activity and alter utilization of various compounds by microorganism. The most apparent example is the microbial degradation of aromatic compounds as oxygenases involved in hydrocarbon degradation contain iron as cofactor, thus imposing specific iron requirement on cells [3]. Under such conditions, microorganisms scavenge extracellular iron by secreting iron-binding compounds called siderophores.
Coastal sand dune plants harbor diverse community of microbes associated with their rhizosphere and roots $[4,5]$. The interactions between plants and bacteria help plants to settle in ecosystem restoration process $[6,7]$. Plant microbe symbioses have been exploited in programs of sand dune restoration. Arbuscular mycorrhizal fungi important to some sand dune plants have been used in restoration projects of coastal sand ecosystems [8]. Despite the role played by bacterial diversity in sand dune plant communities, very few reports are available on the distribution and abundance of rhizosphere-associated bacteria. Park et al. [5] have isolated and characterized bacteria associated with sand dune plant spp. from Korea and further characterized their plant growth-promoting potential [9]. Arun and Sridhar [2] have studied symbiotic performance of fast growing rhizobia isolated from costal sand dunes of Karnataka, India. Microorganisms associated with plants augment their growth by increasing root development, nitrate uptake, solubilizing 
TABLE 1: Iron content of sand dune samples.

\begin{tabular}{lc}
\hline Sand dune sample & \% of Fe \\
\hline R1 & 0.3119 \\
R2 & 0.3098 \\
R3 & 0.3128 \\
R4 & 0.3137 \\
NR1 & 0.3156 \\
NR2 & 0.3156 \\
NR3 & 0.2937 \\
NR4 & 0.2931 \\
\hline
\end{tabular}

phosphorous, or by controlling soil-borne pathogens by competing for limiting nutrients [10]. Siderophore producers indirectly promote plant growth by competing with plant pathogens for iron [11]. A number of plants possess heterologous iron uptake mechanism for acquisition of iron through iron-bacterial siderophore complex [12].

In our earlier studies, we have reported plant growth promotion by bacterial isolates from rhizosphere of Ipomea pes-caprae and Spinifex littoreus [13]. The present study was undertaken to investigate the distribution of siderophoreproducing bacteria in rhizosphere and nonrhizhosphere regions of coastal sand dunes of Miramar, India. Furthermore, we also screened these isolates to determine their ability to degrade sodium benzoate.

\section{Materials and Methods}

2.1. Sample Collection and Determination of Viable Counts. Sand samples were collected from coastal sand dunes of Miramar, Goa located on the west coast of India. Rhizosphere samples were collected from rhizosphere of sand dune creeper Ipomoea pes-caprae and nonrhizosphere samples from areas devoid of sand dune vegetation. Sand dune samples were serially diluted in physiological saline and plated on two different media, nutrient agar (NA) and Tryptone yeast extract glucose agar (TYG). Plates were incubated at room temperature and examined after 24 and $48 \mathrm{hrs}$ for bacterial colony-forming units $\left(\mathrm{cfu} \mathrm{g}^{-1}\right)$. Viable counts were recorded, and predominant isolates were purified and maintained on slants at $4^{\circ} \mathrm{C}$.

2.2. Determination of the Iron Content of the Samples. The digestion of the sand samples for determining iron content was carried out as described by I. Jarvis and K. E. Jarvis [14]. Briefly, $0.2 \mathrm{~g}$ of sand sample was digested with $10 \mathrm{~mL}$ of the mixture of hydrofluoric acid: nitric acid, and perchloric acid $(7: 3: 1)$ and dried on hot plate at $150^{\circ} \mathrm{C}$. After drying, $5 \mathrm{~mL}$ of the above mixture was added and dried on hot plate for 1 hour. $2 \mathrm{~mL}$ of concentrated $\mathrm{HCl}$ was added and dried completely. Residue was dissolved in $10 \mathrm{~mL}$ of $1: 1 \mathrm{HNO}_{3}$, and the contents were diluted to $25 \mathrm{~mL}$ with milli Q water. The concentration of Fe was determined by AAS (Shimadzu 6300).
2.3. Screening for Siderophore Producers. Siderophore production was determined using CAS assay [15]. The medium NA/TYG deferred by adding 8-hydroqxyquinoline dissolved in chloroform to ensure complete removal of $\mathrm{Fe}$ [16]. The isolates were spot inoculated, and plates were incubated till 72 hours, and the isolates forming yellow zone were selected for further studies.

2.4. Selection and Identification of the Isolates. The cultural, morphological, and biochemical characteristics of the isolates producing siderophores were determined, and the isolates were identified based on Bergey's Manual of Systemic Bacteriology $[17,18]$. In addition to biochemical analyses, nine isolates were subjected to partial sequencing of $16 \mathrm{~S}$ rRNA gene. The genomic DNA was extracted as described by Sambrook et al. [19]. 16S rRNA gene was amplified using standard universal forward primer (S-D-Bact-0011-a-5-17: $5^{\prime}$-GTTTGATCCTGGCTCAG-3') and standard universal backward primer (S-*-Univ-1392-b-A-15: 5'-ACGGGCGGTGTGTNC-3'). The derived $16 \mathrm{~S}$ rRNA gene sequence was compared with sequences in the GenBank database using the BLAST search program [20] and aligned by using the multiple alignment Clustal X program [21].

2.5. Screening of the Siderophore Producers for Sodium Benzoate Degradation. Selected isolates were streaked on mineral salts medium (MSM) [22] supplemented with various concentrations of sodium benzoate $(0.1 \%, 0.2 \%, 0.5 \%$, $0.75 \%, 1 \%, 1.5 \%$, and $2 \%$ concentrations). The plates were incubated at $28^{\circ} \mathrm{C}$ up to seven days.

2.6. Spectrophotometric and Spectrofluorimetric Characteristics of Siderophore Produced by the Isolate TMR2.13. TMR2.13 was inoculated in MSM with $0.2 \%$ of glucose, and the flask was incubated at $28^{\circ} \mathrm{C}$ on shaker at $100 \mathrm{rpm}$ for 24 hours. The culture broth was centrifuged, and the supernatant was scanned for peaks in UV-Vis range using spectrophotometer (Shimadzu UV-2450). Fluorimetric analysis was carried out with RF-5301 PC Shimadzu spectrofluorometer at excitation and emission wavelengths of 400 and $467 \mathrm{~nm}$, respectively. Fluorescence quenching was studied by adding $10 \mu \mathrm{L}$ of Fe supernatant to achieve a final concentration of $3.3 \mu \mathrm{M}$ [23].

2.7. Evaluation of Siderophore Production in Presence of Sodium Benzoate in MSM. Flasks containing MSM with $0.2 \%$ of glucose or sodium benzoate as the sole carbon source, supplemented with iron, in increasing concentration $(0,13.5,27$, $54,108,216$, and $432 \mu \mathrm{M}$ ) were inoculated with $5 \%$ of exponential cells grown in the respective medium. All the culture flasks were incubated at $100 \mathrm{rpm}$ at $28^{\circ} \mathrm{C}$, and growth and pigment production was monitored over a period of 72 hours. $5 \mathrm{~mL}$ sample was removed every 8 hours, and growth was measured as increase in turbidity at $600 \mathrm{~nm}$. Siderophore was quantified in cell-free supernatant by noting the absorbance at $400 \mathrm{~nm}$ using UV-Vis spectrophotometer (Shimadzu UV-2450), and siderophore concentration was calculated as described by Gupta et al. [24]. 
TABle 2: (a) Tentative identification siderophore producers. (b) Accession numbers of selected siderophore producers and their closest match.

(a)

\begin{tabular}{|c|c|c|}
\hline Sr. no. & Culture number & Identification \\
\hline (1) & TMR1.6.1 & Bacillus spp. \\
\hline (2) & TMR1.6.2 & Bacillus spp. \\
\hline (3) & TMR1.8 & Bacillus spp. \\
\hline (4) & TMR1.17 & Bacillus spp. \\
\hline (5) & TMR1.18 & Streptomyces spp. \\
\hline (6) & NAMR1.6 & Pseudomonas spp. \\
\hline (7) & NAMR1.8 & Bacillus spp. \\
\hline (8) & TMR2.6 & Streptomyces spp. \\
\hline (9) & TMR2.13 & Pseudomonas aeruginosa \\
\hline (10) & NAMR3.1 & Bacillus spp. \\
\hline (11) & NAMR3.2 & Renibacterium spp. \\
\hline (12) & NAMR3.7 & Renibacterium spp. \\
\hline (13) & NAMR3.8 & Renibacterium spp. \\
\hline (14) & NAMR3.12 & Corynebacterium \\
\hline (15) & NAMR3.13 & Corynebacterium \\
\hline (16) & NAMR3.15 & Azotobacter spp. \\
\hline (17) & NAMR4.8 & Corynebacterium spp. \\
\hline (18) & NAMR4.10 & Bacillus spp. \\
\hline (19) & TMNR1.4 & Kurthia spp. \\
\hline$(20)$ & TMNR2.7.1 & Bacillus spp. \\
\hline$(21)$ & TMNR2.7.2 & Bacillus spp. \\
\hline (22) & TMNR2.7.3 & Bacillus spp. \\
\hline (23) & NAMNR2.1 & Brochothrix spp. \\
\hline (24) & NAMNR2.2 & Brochothrix spp. \\
\hline (25) & TMNR3.3 & Bacillus spp. \\
\hline (26) & NAMNR3.3 & Bacillus spp. \\
\hline (27) & NAMNR3.5 & Bacillus spp. \\
\hline (28) & TMNR4.1.1 & Bacillus spp. \\
\hline (29) & TMNR4.1.2 & Bacillus spp. \\
\hline$(30)$ & NAMNR4.4 & Bacillus spp. \\
\hline
\end{tabular}

(b)

\begin{tabular}{|c|c|c|c|c|}
\hline Sr. no. & Culture number & Biochemically identified as & Accession number & Closest match to \\
\hline (1) & TMR1.6.2 & Bacillus spp. & JN596242 & $\begin{array}{c}\text { EU882849.1 } \\
\text { Bacillus subtilis strain F3-7 }\end{array}$ \\
\hline (2) & TMR1.17 & Bacillus spp. & JN596247 & $\begin{array}{c}\text { HM016080.1 } \\
\text { Bacillus amyloliquefaciens strain KSU-109 }\end{array}$ \\
\hline (3) & TMR1.18 & Streptomyces spp. & JN596248 & $\begin{array}{c}\text { AB184071.1 } \\
\text { Streptomyces sclerotialus strain: NBRC } 12246\end{array}$ \\
\hline (4) & TMR2.6 & Streptomyces spp. & JN596249 & $\begin{array}{c}\text { AB184657.2 } \\
\text { Streptomyces djakartensis strain: NBRC } 15409\end{array}$ \\
\hline (5) & TMR2.13 & Pseudomonas aeruginosa & HM030825 & $\begin{array}{c}\text { GU339295.1 } \\
\text { Pseudomonas aeruginosa strain EH70 }\end{array}$ \\
\hline (6) & NAMR4.10 & Bacillus spp. & JN596242 & $\begin{array}{c}\text { EU746420.1 } \\
\text { Bacillus sp. A-34 }\end{array}$ \\
\hline (7) & TMNR2.7.1 & Bacillus spp. & JN596243 & $\begin{array}{c}\text { HQ238533.1 } \\
\text { Bacillus tequilensis strain S12Ba-171 }\end{array}$ \\
\hline (8) & TMNR2.7.2 & Bacillus spp. & JN596244 & $\begin{array}{c}\text { HQ238638.1 } \\
\text { Bacillus tequilensis strain S433Ba-70 }\end{array}$ \\
\hline (9) & TMNR3.3 & Bacillus spp. & JN596245 & $\begin{array}{c}\text { GU181234.1 } \\
\text { Bacillus amyloliquefaciens strain SRDM2 }\end{array}$ \\
\hline
\end{tabular}



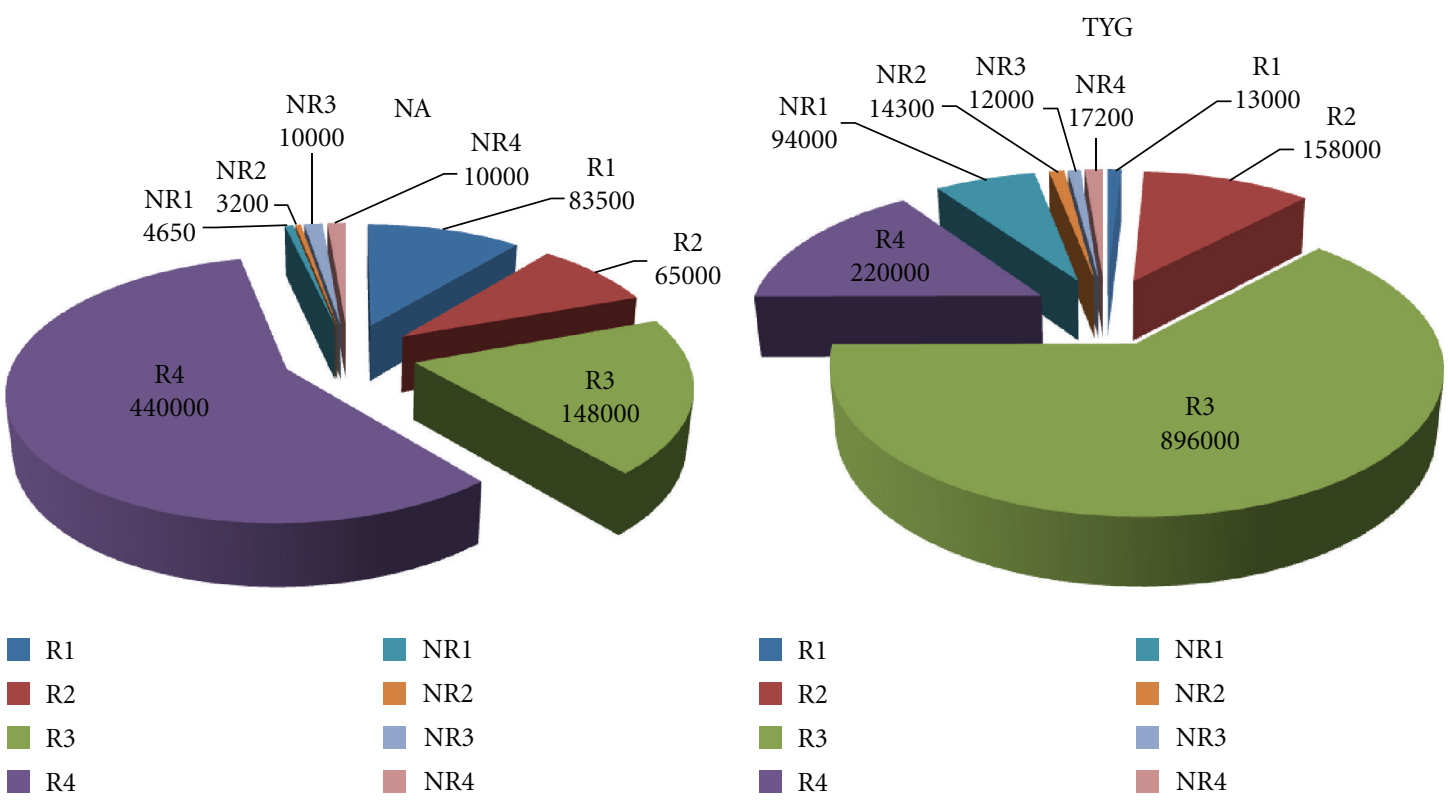

(a)

(b)

Figure 1: (a) Viable count of the sand dune samples on NA. (b) Viable count of the sand dune samples on TYG.

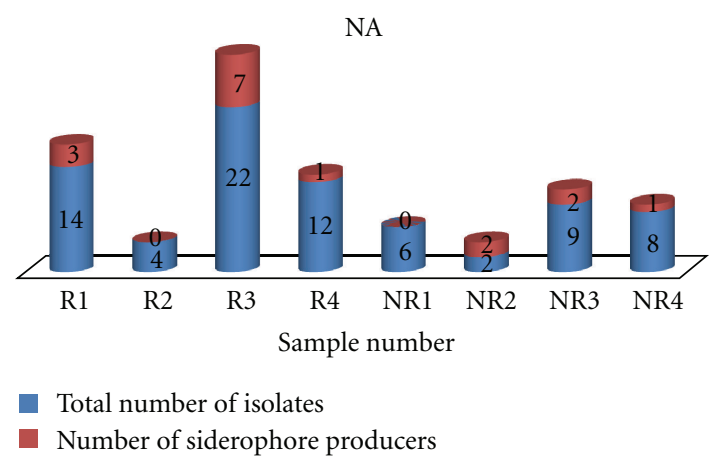

(a)

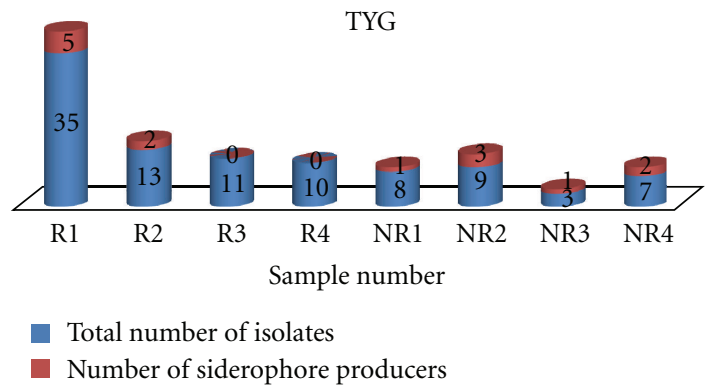

(b)

FIGURE 2: (a) Distribution of the siderophore producers isolated on NA. (b) Distribution of the siderophore producers isolated on TYG.

\section{Results and Discussion}

3.1. Viable Counts. The total viable count of sand dune samples ranged from $9.4 \times 10^{3}$ to $8.96 \times 10^{5} \mathrm{cfu} / \mathrm{g}$ on NA (Figure 1(a)). On TYG, viable count ranged from $3.20 \times 10^{3}$ to $8.96 \times 10^{5} \mathrm{cfu} / \mathrm{g}$ (Figure 1(b)). Higher counts were obtained for rhizosphere samples compared to nonrhizosphere which is expected as plants support microbial growth in their rhizosphere region by increasing release of the exudates [25] or by producing compounds that mimic quorum sensing signals, thus affecting bacterial communities in return [26].

3.2. Iron Content of Samples. Iron content of the samples was found to be low and varied from $0.29 \%$ to $0.31 \%$ (Table 1 ). Studies on quartz grains from a range of environments from continental and coastal dune fields have reported iron-rich clay coatings on the grains [27]. Sand dunes can have very high Fe content as has been reported in Saharan dust which contains up to 8 percent of $\mathrm{Fe}_{2} \mathrm{O}_{3}$ [28].

3.3. Distribution of Siderophore Producers. A total of 173 isolates were obtained, of which 77 were isolated on NA and 96 bacterial strains on TYG. $20.77 \%$ of the total NA isolates were siderophore producers, while $14.58 \%$ of TYG isolates produced CAS detectable siderophore. Comparative study showed that almost an equal fraction of bacterial population isolated from rhizosphere and nonrhizosphere regions on NA were siderophore producers, while a higher fraction of bacterial population from nonrhizosphere region obtained on TYG were siderophore producers (Figures 2(a) and 2(b)).

3.4. Identification of the Selected Isolates. Based on the characteristics, the isolates were identified using Bergey's Manual of Systematic Bacteriology. 16S rRNA gene of nine isolates 
TABLE 3: Growth of isolates on MSM with sodium benzoate.

\begin{tabular}{|c|c|c|c|}
\hline $\begin{array}{l}\text { Sr. } \\
\text { no. }\end{array}$ & $\begin{array}{l}\text { Culture } \\
\text { number }\end{array}$ & $\begin{array}{l}\text { Growth } \\
\text { on } \\
\text { sodium } \\
\text { benzoate }\end{array}$ & $\begin{array}{l}\text { Maximum sodium benzoate } \\
\text { concentration at which the isolates } \\
\text { exhibit growth }\end{array}$ \\
\hline (1) & TMR1.6.1 & - & \\
\hline (2) & TMR1.6.2 & - & \\
\hline (3) & TMR1.8 & - & \\
\hline (4) & TMR1.17 & - & \\
\hline (5) & TMR1.18 & - & \\
\hline (6) & NAMR1.6 & - & \\
\hline (7) & NAMR1.8 & - & \\
\hline (8) & TMR2.6 & - & \\
\hline (9) & TMR2.13 & + & $(2 \%)$ \\
\hline (10) & NAMR3.1 & - & \\
\hline (11) & NAMR3.2 & - & \\
\hline (12) & NAMR3.7 & - & \\
\hline (13) & NAMR3.8 & - & \\
\hline (14) & NAMR3.12 & - & \\
\hline (15) & NAMR3.13 & - & \\
\hline (16) & NAMR3.15 & - & \\
\hline (17) & NAMR4.8 & - & \\
\hline (18) & NAMR4.10 & - & \\
\hline (19) & TMNR1.4 & - & \\
\hline (20) & TMNR2.7.1 & + & $(0.1 \%)$ \\
\hline (21) & TMNR2.7.2 & - & \\
\hline (22) & TMNR2.7.3 & - & \\
\hline (23) & NAMNR2.1 & - & \\
\hline (24) & NAMNR2.2 & - & \\
\hline (25) & TMNR3.3 & - & \\
\hline (26) & NAMNR3.3 & + & $(0.1 \%)$ \\
\hline (27) & NAMNR3.5 & + & $(1 \%)$ \\
\hline (28) & TMNR4.1.1 & + & $(1 \%)$ \\
\hline (29) & TMNR4.1.2 & - & \\
\hline (30) & NAMNR4.4 & + & $(1 \%)$ \\
\hline
\end{tabular}

Key: +: growth, -: no growth.

was sequenced, and the sequences were deposited in GenBank. Of the 30 total siderophore producers isolated, 16 belonged to Bacillus spp accounting for $53.3 \%$ of the total siderophore producers (Tables 2(a) and 2(b)). 3 isolates each belonged to Brochothrix, Corynebacterium, and Renibacterium species. Two species of Streptomyces and Pseudomonas and one species of Kurthia and Azotobacter were detected. The predominance of Bacillus spp. could be due to their ability to form siderophores and resist adverse ecological conditions characteristic of sand dune ecosystems [13]. Bacillus spp. have been reported to promote plant growth in barley [29], pine and spruce [30], and in eggplant [13]. Shin et al. [9] and Park et al. [5] have also reported predominance of Pseudomonas spp. associated with sand dune vegetation.

Our results interestingly showed that the ecosystem harbors a large number of siderophore producers which were detected using the CAS assay. Out of the total 177 isolates, $16.94 \%$ showed siderophore production. It was also significant to note that the nonrhizosphere region also harbored siderophore-producing organisms. Anthropogenic material and marine fauna contributes to the organic material which supports growth of microorganisms. However, the survival of such bacteria is again dependent upon their capacity to adapt. The siderophore-producing organisms are just one such group of bacteria which we report from such environment.

3.5. Degradation of Sodium Benzoate by the Selected Isolates. Of the 30 siderophore producers, 6 isolates were found to grow using sodium benzoate as the sole source of carbon (Table 3). A significant characteristic of the isolate TMR2.13 was its ability to grow on sodium benzoate as sole source of carbon upto a concentration of $2 \%$ along with a production of a yellow green pigment. Phylogenetic analysis of $16 \mathrm{~S}$ rRNA gene of the isolate (accession number: HM030825) showed 96\% similarity (based on BLAST) to Pseudomonas aeruginosa with closest similarity to Pseudomonas aeruginosa (EH70) (GU339295.1) (Figure 3).

3.6. Characteristics of the Siderophore. Cell-free supernatants of TMR2.13, when scanned in spectrophotometer, showed a sharp peak at $400 \mathrm{~nm}$, and spectrofluorimetric analysis of the supernatants demonstrated excitation and emission wavelengths of 400 and $467 \mathrm{~nm}$, respectively. Further, the fluorescence in the supernatant showed quenching with $\mathrm{Fe}^{+2}$ and $\mathrm{Fe}^{+3}$ (Figure 4). Pseudomonas aeruginosa is reported to produce pyoverdine, a yellow fluorescent pigment with strong affinity for iron, and gives absorption maxima at $400 \mathrm{~nm}$ and emission at $460 \mathrm{~nm}[31,32]$. Pyoverdines are the most complex siderophores known to date and represent the primary iron uptake system in fluorescent pseudomonads [33, 34]. Pyoverdine is also reported to have affinity for $\mathrm{Fe}^{+2}$ as well as $\mathrm{Fe}^{+3}$ with $\mathrm{Fe}^{+2}$ binding faster than $\mathrm{Fe}^{+3}$ [23]. With the pigment produced by the isolate TMR2.13, $\mathrm{Fe}^{+2}$ immediately quenched the fluorescence to $45.58 \%$, while $\mathrm{Fe}^{+3}$ quenched the fluorescence to $67.08 \%$ within 30 seconds. Xiao and Kisaalita [23] have also demonstrated that pyoverdines also bind and oxidize $\mathrm{Fe}^{+2}$ with the binding of pyoverdines to $\mathrm{Fe}^{+2}$ being faster than to $\mathrm{Fe}^{+3}$ and suggested that the phenomenon could be due to the precipitation of $\mathrm{Fe}^{+3}$ as $\mathrm{Fe}(\mathrm{OH})_{3}$.

3.7. Effect of Sodium Benzoate on Siderophore Production at Different Concentrations of Iron. During the initial stages of growth, the culture produces siderophore, in MSM with glucose or sodium benzoate. Relation between growth and siderophore production showed simultaneous formation of siderophore during exponential growth phase in the medium with no added iron. Further, growth and siderophore production in glucose and benzoate showed significant differences. The production of siderophore was much higher in the presence of benzoate, $199.071 \mu \mathrm{g} / \mathrm{mL}$, indicating the specific requirement of iron for growth of the organism on the aromatic hydrocarbon (Figure 5).

In MSM with glucose containing 13,27 , and $54 \mu \mathrm{M}$ of added iron, the siderophore appeared only after 8 hours 


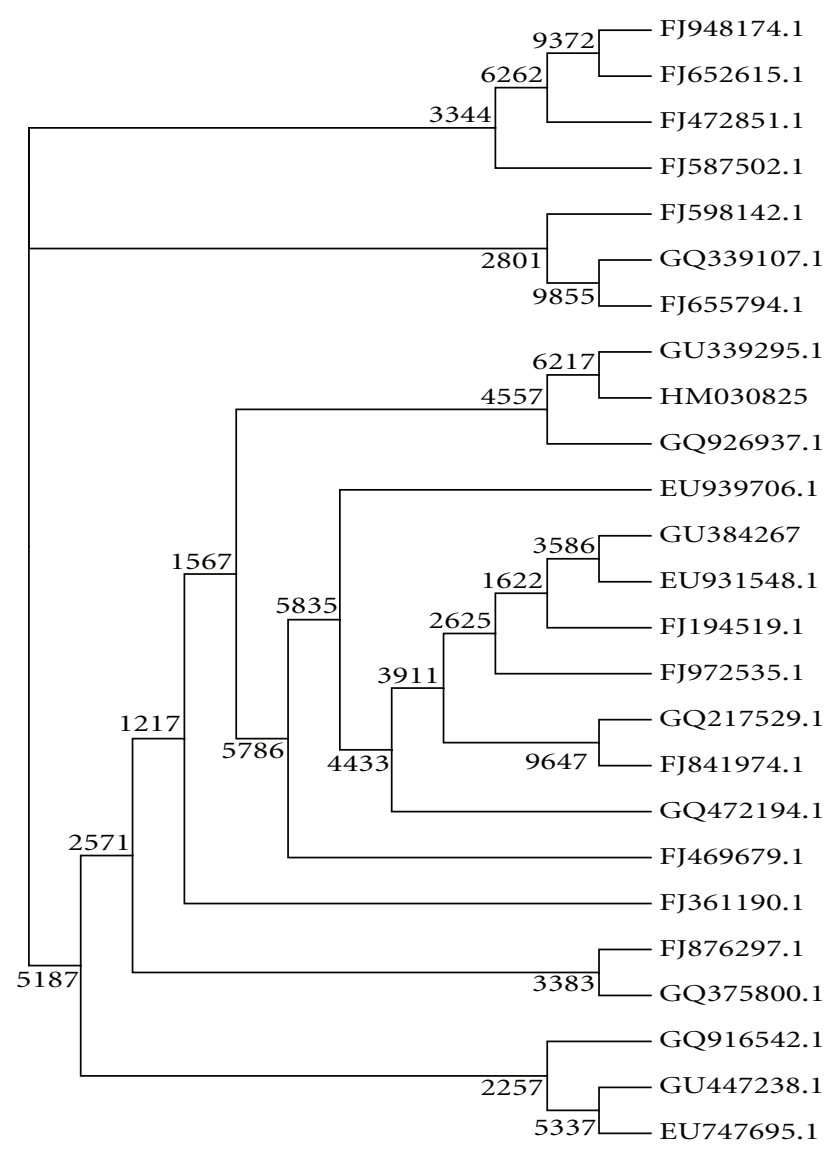

FIGURE 3: Unrooted tree constructed using the neighbour-joining method showing the phylogenetic relationships of Pseudomonas aeruginosa strain TMR2.13 (accession number: HM030825) and other strains of Pseudomonas aeruginosa.

(Figure 6). No siderophore was detected in MSM with 108, 216 , and $432 \mu \mathrm{M}$ of added iron indicating that the iron is sufficient to support the growth on glucose. Further, with sodium benzoate as the carbon source, siderophore production was initiated immediately with $13.5 \mu \mathrm{M}$ of the added $\mathrm{Fe}^{+2}$, while in flasks containing 27, 54, and $108 \mu \mathrm{M}$ of the added iron, the siderophore was detected only after 8, 24, and 40 hours, respectively (Figure 7 ). Further increase in iron concentration $(216$ and $432 \mu \mathrm{M})$ did not show any siderophore production even up to $72 \mathrm{hrs}$. This indicated that iron concentrations beyond $54 \mu \mathrm{M}$ inhibited siderophore production in MSM with glucose. However, the inhibition was noticed at much higher concentration $(108 \mu \mathrm{M})$ in the presence of benzoate.

A report on the effect of trace element requirement has shown that the iron demand in bacteria increases during the expression of alkane hydroxylase [35].A study on the effect of iron concentration on degradation of toluene by Pseudomonas strain reports reduction in the efficiency of the culture when the iron concentration is low [3]. Our observations also suggest the requirement of a higher concentration of iron to sustain growth in benzoate medium. It is a well-established fact that mono- and dioxygenases involved in degradation of aromatic hydrocarbons require iron as the

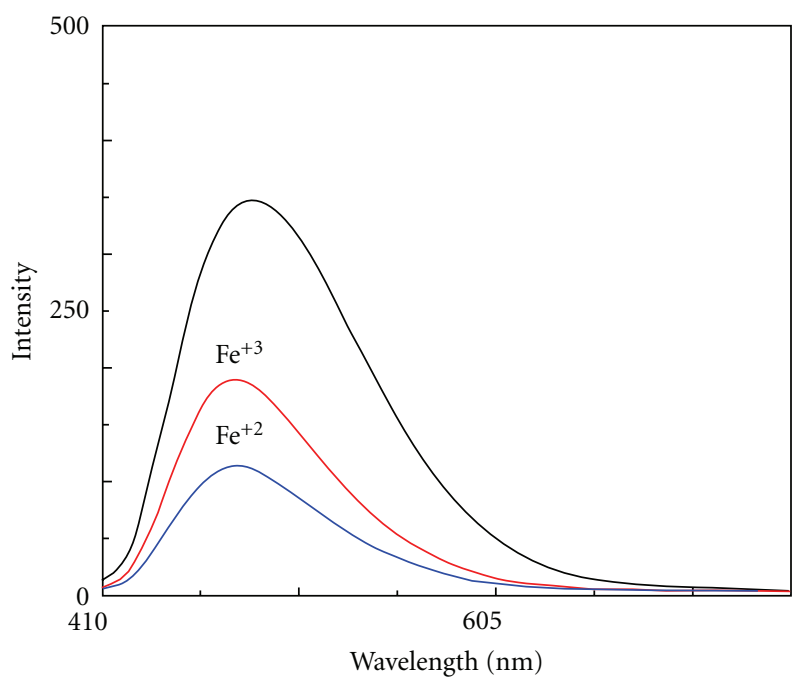

FIGURE 4: Fluorescence spectra of pyoverdine illustrating fluorescence quenching with $\mathrm{Fe}^{+2}$ and $\mathrm{Fe}^{+3}$.

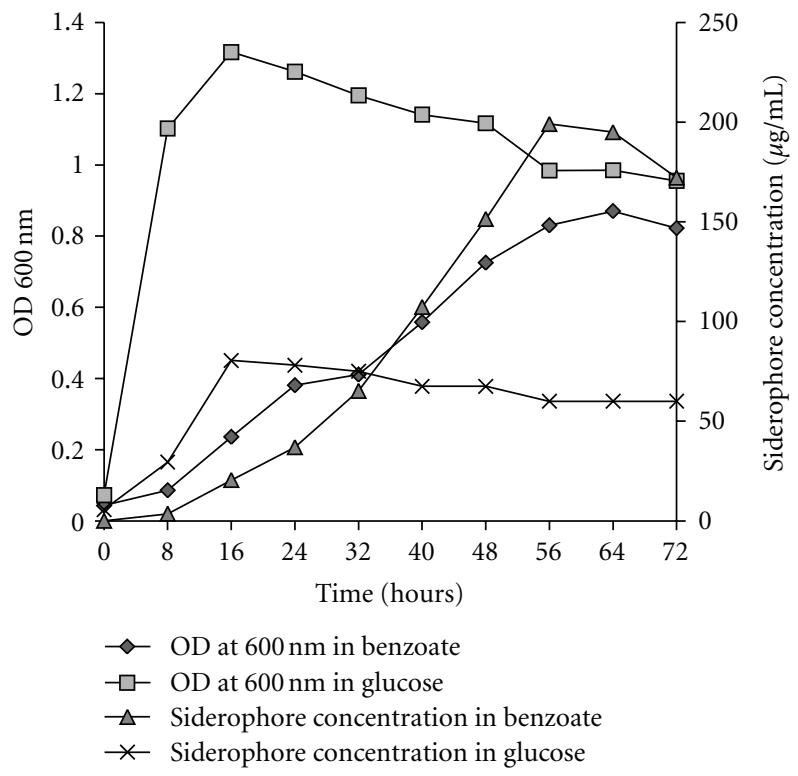

Figure 5: Growth and siderophore production by Pseudomonas aeruginosa in MSM with glucose and sodium benzoate without the added Fe.

cofactor [3]. Earlier studies on the effect of iron concentration on siderophore production by $P$. aeruginosa have shown siderophore production even with $248 \mu \mathrm{M}$ of $\mathrm{Fe}^{+3}$ [33].

Biosynthesis and secretion of siderophore is known to be related to the requirement of the iron for metabolism of the specific growth substrates. The presence of aromatic compound along with easily metabolisable cosubstrates supports the production of siderophores. Iron concentration is one of the many factors influencing efficient cleanup of aromatic pollutants. In natural environments, the availability of iron is usually low, more so, in marine and coastal ecosystem as well as arid environments where the concentration of iron can be as low as $10^{-18} \mathrm{M}[36]$. In such environments, the presence of 


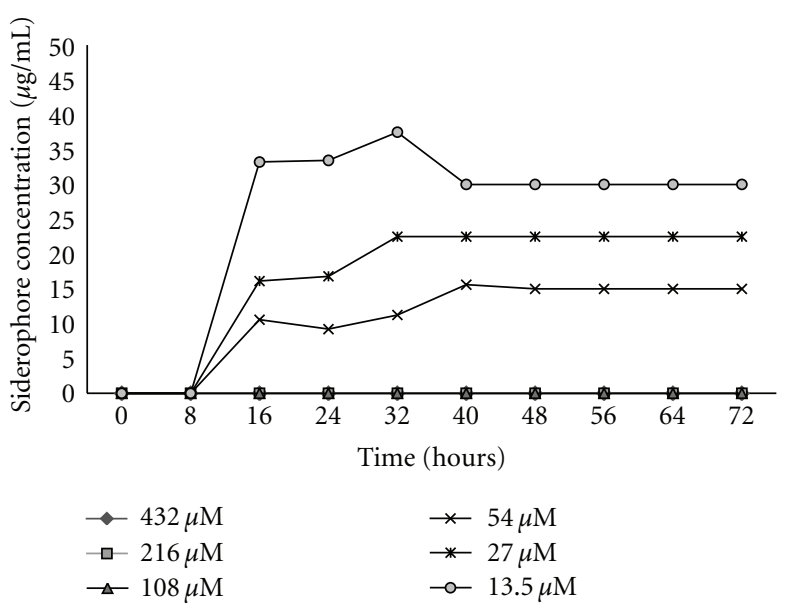

FIGURE 6: Siderophore production in MSM with glucose as the sole carbon source with different iron concentration (13.5-432 $\mu \mathrm{M})$.

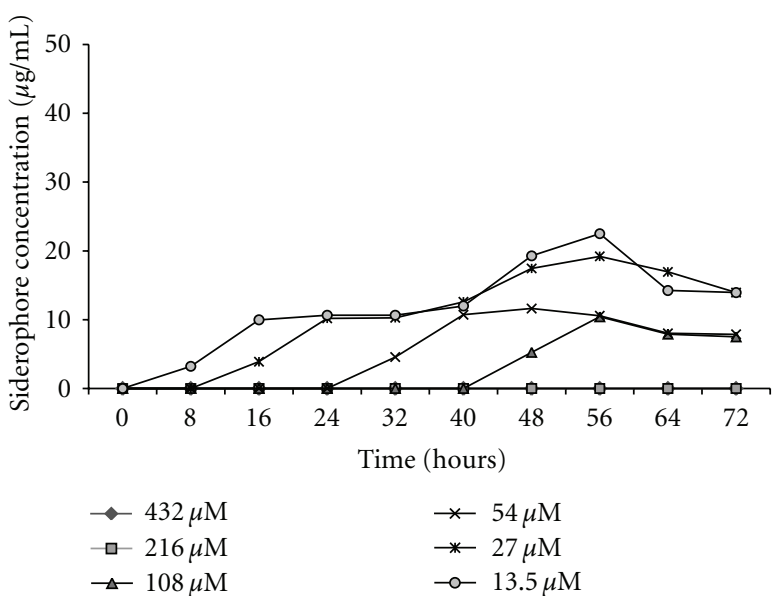

Figure 7: Siderophore production in MSM with sodium benzoate as the sole carbon source with different iron concentration (13.5$432 \mu \mathrm{M})$.

hydrocarbon will promote higher levels of siderophore production to support the hydrocarbon degradation. A direct implication of increased level of siderophores is on microbial community structure, as these siderophores can also support the growth of non-siderophore-producing bacteria which may be beneficial or pathogenic or nonculturable [37].

\section{Acknowledgments}

The authors wish to thank the Centre of Excellence in Marine Microbiology, Ministry of Earth Sciences for the financial assistance provided for this research study. They are grateful to Dr. Ashwani Kumar, officer-in-charge, and Mr. Ajeet Mohanty, assistant research scientist, from Malaria Research Centre Field Station, Goa for providing PCR facility.

\section{References}

[1] A. B. Arun, K. R. Beena, N. S. Raviraja, and K. R. Sridhar, "Coastal sand dunes_-a neglected ecosystem," Current Science, vol. 77, pp. 19-21, 1999.

[2] A. B. Arun and K. R. Sridhar, "Symbiotic performance of fastgrowing rhizobia isolated from the coastal sand dune legumes of west coast of India," Biology and Fertility of Soils, vol. 40, no. 6, pp. 435-439, 2004.

[3] I. J. T. Dinkla, E. M. Gabor, and D. B. Janssen, "Effects of iron limitation on the degradation of toluene by Pseudomonas strains carrying the TOL (pWWO) plasmid," Applied and Environmental Microbiology, vol. 67, no. 8, pp. 3406-3412, 2001.

[4] M. S. Lee, J. O. Do, M. S. Park et al., "Dominance of Lysobacter sp. in the rhizosphere of two coastal sand dune plant species, Calystegia soldanella and Elymus mollis," Antonie van Leeuwenhoek, vol. 90, no. 1, pp. 19-27, 2006.

[5] M. S. Park, S. R. Jung, M. S. Lee et al., "Isolation and characterization of bacteria associated with two sand dune plant species, Calystegia soldanella and Elymus mollis," Journal of Microbio$\log y$, vol. 43, no. 3, pp. 219-227, 2005.

[6] B. R. Glick, "The enhancement of plant growth by free-living bacteria," Canadian Journal of Microbiology, vol. 41, no. 2, pp. 109-117, 1995.

[7] D. Egamberdiyeva, "Characterization of Pseudomonas species isolated from the rhizosphere of plants grown in serozem soil, semi arid region of Uzbekistan," TheScientificWorldJournal, vol. 5, pp. 501-509, 2005.

[8] D. M. Sylvia and N. J. Burks, "Selection of a vesicular-arbuscular mycorrhizal fungus For practical inoculation of Uniola paniculata," Mycologia, vol. 80, pp. 565-568, 1988.

[9] D. S. Shin, M. S. Park, S. Jung et al., "Plant growth-promoting potential of endophytic bacteria isolated from roots of coastal sand dune plants," Journal of Microbiology and Biotechnology, vol. 17, no. 8, pp. 1361-1368, 2007.

[10] S. E. Smith and D. J. Read, Mycorrhizal Symbiosis, Academic Press, San Diego, Calif, USA, 1997.

[11] S. Dobbelaere, J. Vanderleyden, and Y. Okon, "Plant growthpromoting effects of diazotrophs in the rhizosphere," Critical Reviews in Plant Sciences, vol. 22, no. 2, pp. 107-149, 2003.

[12] A. Sharma, B. N. Johri, A. K. Sharma, and B. R. Glick, "Plant growth-promoting bacterium Pseudomonas sp. strain GRP3 influences iron acquisition in mung bean (Vigna radiata L. Wilzeck)," Soil Biology and Biochemistry, vol. 35, no. 7, pp. 887-894, 2003.

[13] A. Godinho, R. Ramesh, and S. Bhosle, "Bacteria from sand dunes of Goa promoting growth in Eggplant," World Journal of Agricultural Sciences, vol. 6, no. 5, pp. 555-564, 2010.

[14] I. Jarvis and K. E. Jarvis, "Rare-earth element geochemistry of standard sediments: a study using inductively coupled plasma spectrometry," Chemical Geology, vol. 53, no. 3-4, pp. 335-344, 1985.

[15] B. Schwyn and J. B. Neilands, "Universal chemical assay for the detection and determination of siderophores," Analytical Biochemistry, vol. 160, no. 1, pp. 47-56, 1987.

[16] W. S. Waring and C. H. Werkman, "Growth of bacteria in an iron free medium," Archive of Biochemistry, vol. 1, pp. 303310, 1942.

[17] R. N. Krieg and G. J. Holt, Bergey's Manual of Systematic Bacteriology, vol. 1, Williams \& Wilkins, 1984. 
[18] A. H. P Sneath, S. N. Mair, and E. M. Sharpe, Bergey's Manual of Systematic Bacteriology, vol. 1 of Bacteriology Symposium, Series No. 2, Williams \& Wilkins, Academic Press, London, UK, New York, NY, USA, 1986.

[19] J. Sambrook, E. F. Fritsch, and T. Maniatis, Molecular Cloning: A Laboratory Manual, Cold Spring Harbour Press, New York, NY, USA, 1989.

[20] S. F. Altschul, W. Gish, W. Miller, E. W. Myers, and D. J. Lipman, "Basic local alignment search tool," Journal of Molecular Biology, vol. 215, no. 3, pp. 403-410, 1990.

[21] J. D. Thompson, T. J. Gibson, F. Plewniak, F. Jeanmougin, and D. G. Higgins, "The CLUSTAL X windows interface: flexible strategies for multiple sequence alignment aided by quality analysis tools," Nucleic Acids Research, vol. 25, no. 24, pp. 4876-4882, 1997.

[22] C. Parulekar and S. Mavinkurve, "Formation of of orthobenzoquinone from sodium benzoate by Pseudomonas mendocina $\mathrm{P}_{2} \mathrm{~d}$," Indian Journal of Experimental Biology, vol. 44, no. 2, pp. 157-162, 2006.

[23] R. Xiao and W. S. Kisaalita, "Fluorescent pseudomonad pyoverdines bind and oxidize ferrous ion," Applied and Environmental Microbiology, vol. 64, no. 4, pp. 1472-1476, 1998.

[24] V. Gupta, K. Saharan, L. Kumar, R. Gupta, V. Sahai, and A. Mittal, "Spectrophotometric ferric ion biosensor from Pseudomonas fluorescens Culture ," Biotechnology and Bioengineering, vol. 100, pp. 284-296, 2007.

[25] D. A. Phillips, T. C. Fox, M. D. King, T. V. Bhuvaneswari, and L. R. Teuber, "Microbial products trigger amino acid exudation from plant roots," Plant Physiology, vol. 136, no. 1, pp. 28872894, 2004.

[26] W. D. Bauer and U. Mathesius, "Plant responses to bacterial quorum sensing signals," Current Opinion in Plant Biology, vol. 7, no. 4, pp. 429-433, 2004.

[27] J. E. Bullard and K. White, "Dust production and the release of iron oxides resulting from the aeolian abrasion of natural dune sands," Earth Surface Processes and Landforms, vol. 30, no. 1, pp. 95-106, 2005.

[28] A. S. Goudie and N. J. Middleton, "Saharan dust storms: nature and consequences," Earth-Science Reviews, vol. 56, no. 1-4, pp. 179-204, 2001.

[29] M. Y. Canbolat, B. Serdar, A. Ramazan, A. Fikretin, and A. Adil, "Effect of plant growth promoting bacteria and soil composition on barley seedling growth, nutrient uptake, soil properties and rhizhosphere microflora," Biology and Fertility of Soils, vol. 42, pp. 350-357, 2006.

[30] M. Shishido, H. B. Massicotte, and C. P. Chanway, "Effect of plant growth promoting Bacillus strains on pine and spruce seedling growth and mycorrhizal infection," Annals of Botany, vol. 77, no. 5, pp. 433-441, 1996.

[31] A. Braud, M. Hannauer, G. L. A. Mislin, and I. J. Schalk, "The Pseudomonas aeruginosa pyochelin-iron uptake pathway and its metal specificity," Journal of Bacteriology, vol. 191, no. 11, pp. 3517-3525, 2009.

[32] P. Cornelis, S. Matthijs, and L. Van Oeffelen, "Iron uptake regulation in Pseudomonas aeruginosa," BioMetals, vol. 22, no. 1, pp. 15-22, 2009.

[33] M. E. Díaz de Villegas, P. Villa, and A. Frías, "Evaluation of the siderophores production by Pseudomonas aeruginosa PSS," Revista Latinoamericana de Microbiologia, vol. 44, no. 3-4, pp. 112-117, 2002.

[34] P. Visca, F. Imperi, and I. L. Lamont, "Pyoverdine siderophores: from biogenesis to biosignificance," Trends in Microbiology, vol. 15, no. 1, pp. 22-30, 2007.
[35] I. E. Staijen and B. Witholt, "Synthesis of alkane hydroxylase of Pseudomonas oleovorans increases the iron requirement of alk $^{+}$bacterial strains," Biotechnology and Bioengineering, vol. 57, no. 2, pp. 228-237, 1998.

[36] V. Braun and H. Killmann, "Bacterial solutions to the ironsupply problem," Trends in Biochemical Sciences, vol. 24, no. 3, pp. 104-109, 1999.

[37] A. D’Onofrio, J. M. Crawford, E. J. Stewart et al., “Siderophores from neighboring organisms promote the growth of uncultured bacteria," Chemistry and Biology, vol. 17, no. 3, pp. 254-264, 2010. 

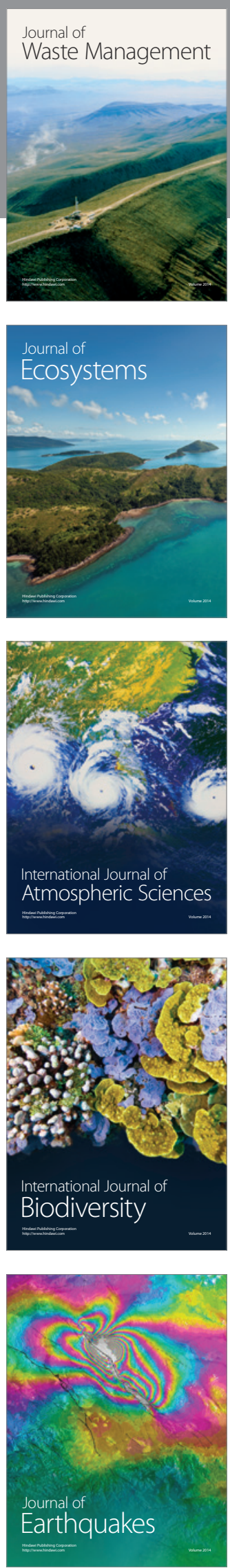
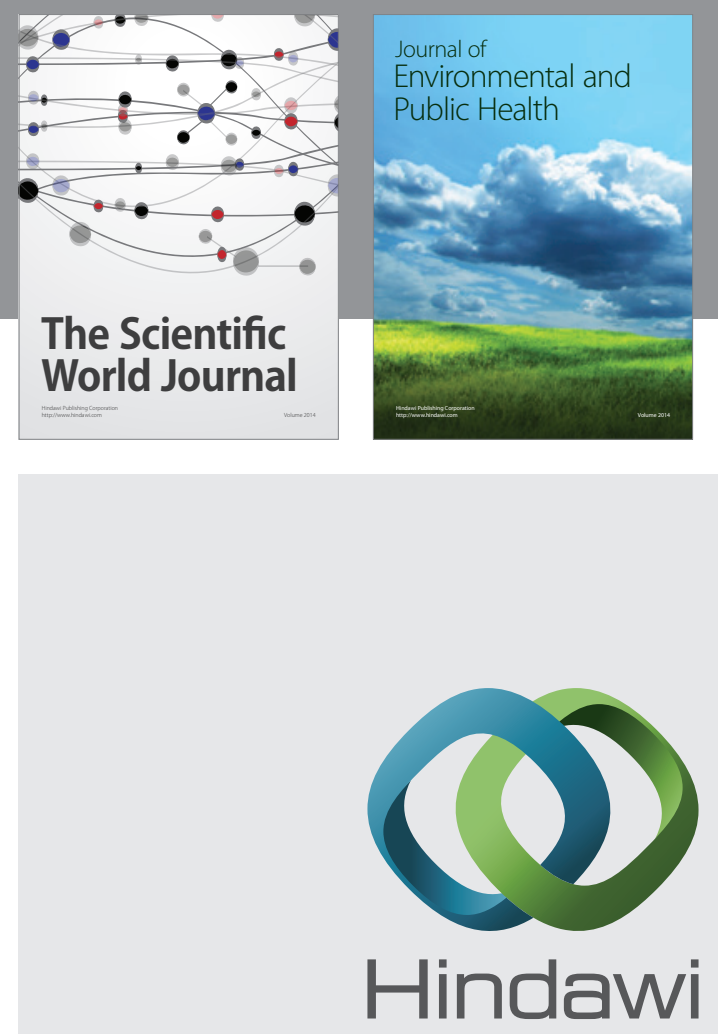

Submit your manuscripts at

http://www.hindawi.com
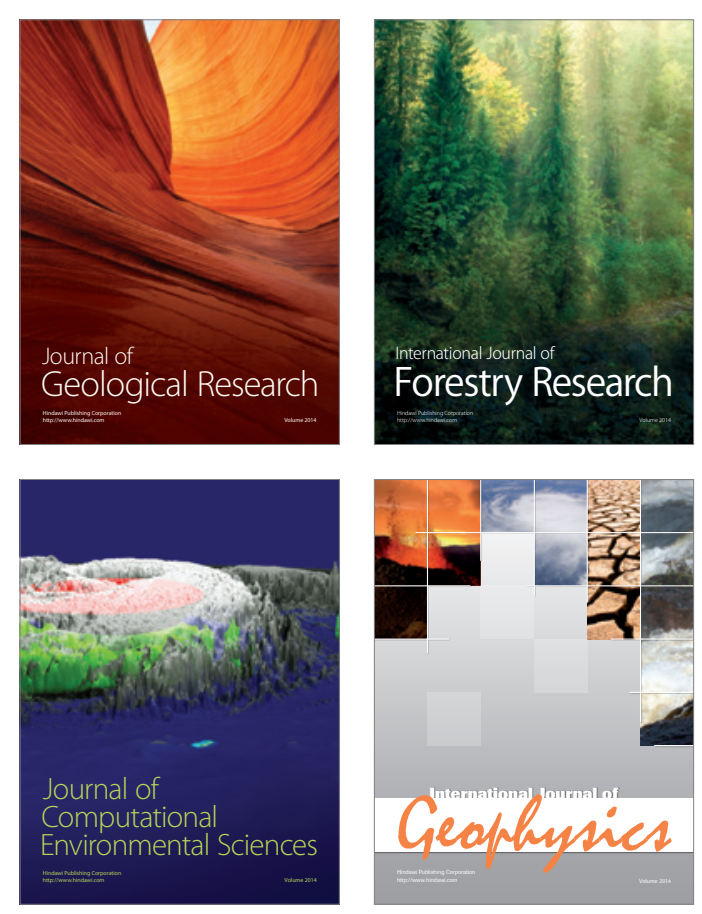
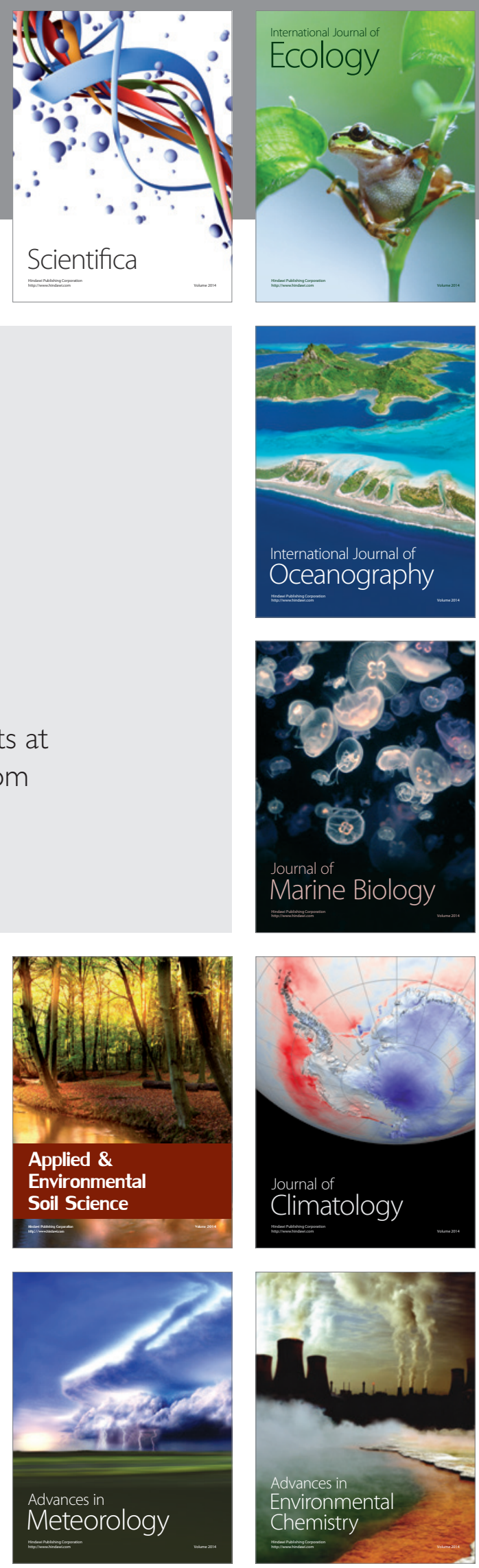